\title{
Oral Nifedipine Versus Intravenous Labetalol in the Management of Severe Pregnancy Induced Hypertension: A Randomized Control Trial
}

\author{
Farah Naz Mabud ${ }^{1 *}$ \\ Serajun Noor ${ }^{1}$ \\ Shahanara Chowdhury ${ }^{2}$
}

'Department of Obstetrics \& Gynaecology Chattogram Maa-O-Shishu Hospital Medical College Chattogram, Bangladesh.

${ }^{2}$ Department of Obstetrics \& Gynaecology Chittagong Medical College

Chattogram, Bangladesh.

\footnotetext{
${ }^{*}$ Correspondence to:

Dr. Farah Naz Mabud

Assistant Professor

Department of Obstetrics \& Gynaecology Chattogram Maa-O-Shishu Hospital Medical College Chattogram, Bangladesh.

Mobile : +8801678221144

Email : farah.naz.mabud@gmail.com
}

Date of Submission ： 21.12 .2020

Date of Acceptance ： 28.01 .2021

www.banglajol.info/index.php/CMOSHMCJ

\begin{abstract}
Background : Pregnancy-also known as gestation is the time during which one or more offspring develops inside a woman. A multiple pregnancy involves more than one offspring, such as with twins. Pregnancy usually occurs by sexual intercourse, but can occur through assisted reproductive technology protedures. To assess the efficacy of oral Nifedipine and I/V Labetalol for lowering BP in severe PIH after 28 weeks of pregnancy.
\end{abstract}

Materials and methods: In this study 100 subjects were selected with severe pregnancy induced hypertension as per inclusion criteria. After taking informed written consent they were randomly allocated into two groups, $A$ \& B. Group A received initially tablet nifedipine $10 \mathrm{mg}$ orally with repeated doses of $20 \mathrm{mg}$ every 20 minutes upto five doses while Group B received intravenous labetalol $20 \mathrm{mg}$ initially followed by escalating doses of $40,80,80$ and $80 \mathrm{mg}$ every 20 minutes until the therapeutic goal blood pressure Systolic $\leq 150 \mathrm{mmHg}$ \& diastolic $\leq 100 \mathrm{mmHg}$ was achieved. Primary outcomes were the time interval and the number of doses needed to achieve a blood pressure of $\leq 150 / 100 \mathrm{mmHg}$, Secondary outcomes were fetomaternal safety, efficacy and side effects of both drugs. The outcomes were recorded in a preformed data collection sheet. All the data were analyzed by computer based software SPSS version 19 (SPSS Inc, Chicago, IL, USA). P <0.05 at 95\% level was taken as statistically significant.

Results: A total of 100 patients of different ages with mean age of 27.41 years were taken in the study. Primi patients were more in Group A the Group B and mode of delivery was commonly caesarian section (66\% vs $78 \%$ ) in both groups. Proportion of target BP achievement were $100 \%$ in Group A and it was $72 \%$ in Group B. Need of drug dose and time of reduction was found significantly less among Group A women. Change of mean $\pm S D$, SBP was more rapid in Group A ( $174.90 \pm 20.01$ vs 158.40 \pm 11.13 ) women who were on Group A oral nifedipine than Group B ( $179.80 \pm 16.54$ vs $167.40 \pm 15.02) \mathrm{i} / \mathrm{v}$ labetalol group after first dose. It was same for DBP also. Need of mean dose were less in group $A$ than Group $B$ (1.72 vs 3.30) also total time needed to achieve target BP was less in Group A (34.40 vs 66.0 mins). There was no need of doses exceeding third dose who were on oral nifidipine than i/v labetolol. Both maternal and fetal heart rate was not influenced by both the drugs. Side effects of drugs were found more in Group B (8\% vs 4\%) and fetal death also more common in there (8\% vs 16\%). Value of APGAR scores was found higher both at 1 minute and at 5 minutes among Group A neonates than Group B. Significant urine output volume was found in Group A patients than Group B at first hour.

Conclusion: Oral nifedipine and intravenous labetalol both the regimens are found to be effective in the management of severe PIH. But Nifidipine lowers blood pressure more rapidly with fewer doses with minimum fetomaternal side-effects.

Key words: Hypertension; Labetalol; Nifedipine; Pregnancy induced hypertension. 


\section{INTRODUCTION}

Pregnancy induced hypertension complicates almost $10 \%$ of pregnancies ${ }^{1}$. Progression from mild to severe forms of hypertension during pregnancy is unpredictable and can be rapid. Overall pre-eclampsia complicates $5 \%-6 \%$ of pregnancies. Maternal complication of acute hypertension in pregnancy includes placental abruption, intra abdominal haaemorrhage, HELLP syndrome, acute LVF, CVA, cardiac failure, renal failure, and multi-organ failure ${ }^{2}$. The fetus is also at risk of growth restriction, pre-maturity, asphyxia and IUD due to placental abruption. In Bangladesh pre-eclampsia and eclampsia is responsible for $16 \%$ of maternal death and $28 \%$ of perinatal mortality ${ }^{3}$.

Management of PIH differs from that of hypertension in nonpregnant individuals. The major goal of antihypertensive medication in severe PIH is to prevent or treat severe hypertension (Generally defined as Blood Pressure (BP) of $\geq 160 / 110 \mathrm{~mm}$ $\mathrm{Hg}$ ) and its associated complications and to prolong the pregnancy till the fetal maturity ${ }^{4}$.

The use of anti-hypertensive drugs in pregnancy is controversial and the choice of antihypertensive drugs in severe PIH is also often limited due to fetal safety concern. Three antihypertensive drugs- Nifedipine, hydralazine and iv labetalol have been demonstrated to be safe for use in the pregnant women ${ }^{5-9}$. Hydralazine a potent arterial vasodilator has long been the criterion standard of therapy for the management of severe PIH complicating pregnancy. As its response is unpredictable and had adverse effects on fetus it is not generally used as a first line agent now in severe $\mathrm{PIH}^{10}$. Nifedipine is a calcium channel blocker, most commonly used for control of sudden rise of BP in the management of severe PIH because of its easy availability, rapid onset of action, ease of oral administration and satisfactory reduction of $\mathrm{BP}^{11}$. Labetalol is a combined alpha- and betablocker and has the advantage over other beta blockers due to its additional arteriolar vasodilator action that helps to lower peripheral vascular resistance with little or no decrease in cardiac output and the rapidity of its action ${ }^{12}$. All these three drugs lacks the proof of superiority of one drug over other which reflects insufficient evidence because of lack of data ${ }^{13}$. In Bangladesh, there are a number of trials comparing inj Hydralazine with either oral Nifedipine or $\mathrm{i} / \mathrm{v}$ labetalol, but there are few trials comparing oral Nifedipine and iv labetalol for control of BP in severe PIH.

So this prospective study is designed to evaluate the comparative safety and effectiveness of oral Nifedipine and iv Lebatalol monotherapy in patients with severe PIH. In our rural area where the availability and cost of inj Labetalol is a question - so if the oral Nifedipine is found to be superior over iv Labetalol, it can be used more extensively and a large number of pregnant women might be benefited.

\section{MATERIALS AND METHODS}

This randomized control study was performed in Chittagong Medical College Hospital, Chattogram from January 2014 to December 2014. A total 100 patients who were presented to us with severe pregnancy induced hypertension after 28 weeks of pregnancy were recruited in the study after taking written informed consent and proper counseling in accordance with the inclusion criteria. Ethical approval was taken from the ethical committee of the institute.

\section{Inclusion criteria:}

i) All conscious patients admitting in the ward with severe pregnancy induced hypertension.

ii) Gestational age after 28 weeks.

iii) Maternal pulse rate between $60-100 \mathrm{~b} / \mathrm{min}$.

\section{Exclusion criteria:}

i) Previous history of hypertension, with complications like heart failure, heart block.

ii) Secondary or non pregnancy related HTN.

iii) Bronchial asthma.

A total of 100 samples were included where 50 received oral Nifedipine and 50 received iv labetalol, considering the drop out we allowed 115 patients were recruited initially. Proper informed consents were obtained and filling up of data sheets were done. After the primary enrollment, 7 patients left the hospital, 5 patients refused to take injection labetalol, 1 patient developed LVF and 2 patients developed pulmonary oedema and were shifted to ICU. The samples were randomized into 2 study groups. The patients who took tablet Nifedipine were labeled as case \& Study group-A, those who received intravenous Labetalol were labeled as Control \& Study group-B.

Randomization was done by lottery method $\&$ the drugs were given to the patients by single blinding method. Group-A patients received oral Nifedipine $10 \mathrm{mg}$ stat, followed by $20 \mathrm{mg}$ every 20 minutes for up to maximum of 5 doses or $90 \mathrm{mg}$ till the desired blood pressure of 150/100 $\mathrm{mmHg}$ was achieved. Once the target B.P was achieved, patients received a maintenance dose of tablet Nifedipine SR, 12 hourly. Group-B patients were administered $20 \mathrm{mg}$ i/v Labetalol stat, followed by escalating doses of $40 \mathrm{mg}, 80 \mathrm{mg}, 80 \mathrm{mg}, 80 \mathrm{mg}$ every 20 minutes up to a maximum of $300 \mathrm{mg}$ till the desired blood pressure of $150 / 100$ $\mathrm{mmHg}$ was achieved. Once the target B.P was achieved, patients received a maintenance dose of oral Labetalol 100mg, 12 hourly. Once the patients were enrolled, blood pressure, pulse rate were recorded every 20 minutes. Volume of urine output was also recorded after collected in an urobag through a Foley catheter. Treatment was considered as failure if the blood pressure did not decrease even after increasing the doses to maximum. Additional antihypertensive agents such as Inj. Hydralazine was added and managed accordingly.
Primary outcomes were:
- Level of systolic BP
- Level of diastolic BP
- Time taken to reach target BP
- Total dose needed to reach target BP
- Demographinc profile
- Outcome of mother and fetus. 
Secondary outcomes were :

- Safety and efficacy of both drugs

- Apgar score at $1 \mathrm{~min}>7$ or $<7$, at $5 \min >7$ or $<7$

- Urinary output at first hour.

Time interval and the number of doses required to achieve the goal therapeutic blood pressure of $<-150 \mathrm{mmHg}$ diastolic $<-100$ $\mathrm{mmHg}$ were recorded. Monitoring of FHR and its abnormality, adverse maternal side effects such as headache, nausea, respiratory distress were noted. After successful control of blood pressure, delivery of the baby was expedited either by induction of labour or by caesarian section immediately or two to three days later. Additional neonatal outcome - APGAR SCORE at 1minutes and at 5 minutes $<7$ or $>7$ was noted. The outcomes were recorded in a preformed data collection sheet. All the data were analyzed by computer based software SPSS version 19 (SPSS Inc, Chicago, IL, USA). $\mathrm{p}<0.05$ at $95 \%$ level was taken as statistically significant.

\section{RESULTS}

In a study period of January 2014 to December 2014, a total 115 were primarily enrolled in the study. 100 patients were finally included in the analysis after drop out. 50 of them received tablet Nifedipine, while 50 received inj. Labetalol. The subject characteristics in two groups were similar with no statistically significant difference between ages, parity, gestational age at delivery. A mean age of 27.41 years were taken in the study. Primi patients were more in Group A than the Group B. Family history of hypertension was more common in Group B patients than Group A, Mode of delivery was commonly caesarian section (66\% vs 78\%) in both groups. Proportion of target BP achievement were $100 \%$ in Group A and it was $72 \%$ in Group B $(\mathrm{p}<0.05)$. Change of mean $\pm \mathrm{SD}$, SBP was more rapid in Group A ( $174.90 \pm 20.01$ vs $158.40 \pm 11.13)$ women who were on Group A oral nifedipine than Group B ( $179.80 \pm$ 16.54 vs $167.40 \pm 15.02) \mathrm{i} / \mathrm{v}$ labetalol group after first dose. It was same for DBP also. Need of mean dose were less in group A than Group B (1.72 vs 3.30) also total time needed to achieve target BP was less in Group A (34.40 vs 66.0 mins). There was no need of doses exceeding third dose who were on oral nifidipine than $i / v$ labetolol. Both maternal and fetal heart rate was not influenced by both the drugs $(p>0.05)$. Maternal side effects of drugs though minor were found more in Group B (8\% vs $4 \%)$. Fetal death was also more common in there $(8 \%$ vs $16 \%$ ). Value of APGAR scores was found higher both at $1 \mathrm{mi}-$ nute and at 5 minutes among Group A neonates than Group B. Urine output was significantly increased $(\mathrm{p}<0.001)$ at one hour after nifedipine therapy $(91.20 \pm 2.20)$ compared with labetalol $(42.20 \pm 3.10 \mathrm{ml})$.
Table I : Distribution of socio-demographic variables among the study groups (With $\chi^{2} \&$ t-test significance).

\begin{tabular}{|c|c|c|c|c|c|c|c|c|}
\hline \multirow{3}{*}{\multicolumn{2}{|c|}{ Socio-demographic Variables }} & \multicolumn{4}{|c|}{ Study Groups } & & \multirow{3}{*}{$\begin{array}{l}\text { Total } \\
\%\end{array}$} & \multirow{3}{*}{$\begin{array}{c}\chi^{2} \text { Test } \\
\text { Significance }\end{array}$} \\
\hline & & \multicolumn{2}{|c|}{ Group A } & \multicolumn{2}{|c|}{ Group B } & & & \\
\hline & & $\mathrm{n}$ & $\%$ & $\mathrm{n}$ & $\%$ & $\mathrm{n}$ & & \\
\hline \multirow[t]{3}{*}{ Age in Groups } & $>20$ Years & 06 & 12.0 & 02 & 4.0 & 08 & 8.0 & $\chi^{2}=2.177$ \\
\hline & $20-30$ Years & 30 & 60.0 & 33 & 66.0 & 63 & 63.0 & $p=0.337$ \\
\hline & $>30$ Years & 14 & 28.0 & 15 & 30.0 & 29 & 29.0 & \\
\hline \multirow[t]{2}{*}{ Locality } & Urban & 30 & 60.0 & 28 & 56.0 & 58 & 58.0 & $\chi^{2}=0.164$ \\
\hline & Rural & 20 & 40.0 & 22 & 44.0 & 42 & 42.0 & $p=0.685$ \\
\hline \multicolumn{9}{|l|}{ Socio-economic } \\
\hline \multirow[t]{3}{*}{ Status } & Upper Middle Class & 08 & 16.0 & 07 & 14.0 & 15 & 15.0 & \\
\hline & Lower Middle Class & 14 & 28.0 & 11 & 22.0 & 25 & 25.0 & $\chi^{2}=0.667$ \\
\hline & Lower Class & 28 & 56.0 & 32 & 64.0 & 60 & 60.0 & $\mathrm{P}=0.414$ \\
\hline \multicolumn{9}{|c|}{ Group A = Oral Nifedipine; Group B = IV Labetalol } \\
\hline \multirow[t]{4}{*}{ Age (Years) } & & $\mathrm{n}$ & Mean & $\pm \mathrm{Sd}$ & Median & & Range & Sign.* \\
\hline & Group A & 50 & 26.14 & 6.26 & 25.00 & $19-$ & & $\mathrm{p}>0.05$ \\
\hline & Group B & 50 & 28.48 & 5.71 & 28.50 & $19-$ & & Not \\
\hline & Total & 100 & 27.31 & 6.08 & 27.00 & $19-$ & & Significan \\
\hline
\end{tabular}

* Independent sample $\mathrm{t}$ - test.

Table II : Distribution of family, personal \& obstetric histories among the study groups (With $\chi^{2}$ test significance).

\begin{tabular}{|c|c|c|c|c|c|c|c|c|}
\hline \multirow{3}{*}{$\begin{array}{l}\text { Family \& } \\
\text { personal } \\
\text { histories }\end{array}$} & & \multicolumn{4}{|c|}{ Study Groups } & \multirow[t]{2}{*}{ Total } & \multicolumn{2}{|c|}{$\chi^{2}$ Test Significance } \\
\hline & \multicolumn{3}{|c|}{ Group A } & \multicolumn{2}{|c|}{ Group B } & & & \\
\hline & $\mathrm{n}$ & $\%$ & n & $\%$ & n & $\%$ & & \\
\hline Family $\mathrm{H} / 0$ & Yes & 04 & 8.0 & 17 & 34.0 & 21 & 21.0 & $\chi^{2}=10.187$ \\
\hline $\begin{array}{l}\text { Hypertension } \\
\text { H/o Using }\end{array}$ & No & 46 & 92.0 & 33 & 66.0 & 79 & 79.0 & $p=0.001$ \\
\hline Cortico-steroids & Yes & 33 & 66.0 & 26 & 52.0 & 59 & 59.0 & $\chi^{2}=2.026$ \\
\hline & No & 17 & 34.0 & 24 & 48.0 & 41 & 41.0 & $\mathrm{p}=0.155$ \\
\hline $\mathrm{H} / 0$ Using & & & & & & & & \\
\hline Mag-Sulf & Yes & 50 & 100.0 & 50 & 100.0 & 100 & 100.0 & - \\
\hline & No & 00 & 0.0 & 00 & 0.0 & 00 & 0.0 & \\
\hline
\end{tabular}

Table II showing personal and family history where family history of hypertension was more common in Group B patients than Group A, injection corticosteroid was used more in Group A.

Table III : Distribution of obstetrics variables among the study groups $(\mathrm{n}=100)$.

\begin{tabular}{llrrrrrrrr} 
Obstetric & & \multicolumn{4}{c}{ Study Groups } & & Total & $\chi^{2}$ Test \\
histories & & Group A & Group B & & & Significance \\
& & n & $\%$ & n & $\%$ & n & $\%$ & \\
Gravida & Primi & 19 & 38.0 & 14 & 28.0 & 33 & 33.0 & $\chi^{2}=1.131$ \\
& Multi & 31 & 62.0 & 36 & 72.0 & 67 & 67.0 & $\mathrm{p}=0.288$ \\
Period of & $28-32$ Wks & 04 & 8.0 & 04 & 8.0 & 08 & 8.0 & $\chi^{2}=4.483$ \\
Amenorrhea & $32-36$ Wks & 14 & 28.0 & 24 & 48.0 & 38 & 38.0 & $\mathrm{p}=0.106$ \\
& $>36$ Wks & 32 & 64.0 & 22 & 44.0 & 54 & 54.0 & \\
Mode of & Vaginal Delivery & 17 & 34.0 & 11 & 22.0 & 28 & 28.0 & $\chi^{2}=1.786$ \\
Delivery & Caesarian Section & 33 & 66.0 & 39 & 78.0 & 72 & 72.0 & $\mathrm{P}=0.181$ \\
\hline
\end{tabular}


Table III showing obstetric variables of the study women where primi was more in Group A than Group B, 32-36 weeks amenorroea was $28 \%$ in Group A and 48\% in Group B, mostly $>36$ weeks of amenorrhoea was found $64 \%$ in group A and $44 \%$ in Group B and mode of delivery was mostly caesarian section in both groups.

Table IV A: Distribution of target related variables among the study groups (With $\chi^{2} \& \mathrm{t}$-test significance).

\begin{tabular}{llrrrrrrr} 
Target & & \multicolumn{4}{c}{ Study Groups } & Total & $\begin{array}{c}\chi^{2} \text { Test } \\
\text { variables }\end{array}$ \\
& & \multicolumn{2}{c}{ Group A } & Group B & & & Significance \\
Target BP & Achieved & 50 & 100.0 & 36 & 72.0 & 86 & 86.0 & $\chi^{2}=16.279$ \\
& Not Achieved & 00 & 0.0 & 14 & 28.0 & 14 & 14.0 & $\mathrm{P}=0.000$ \\
Total Dose & <2 Doses & 20 & 40.0 & 08 & 16.0 & 28 & 28.0 & $\chi^{2}=30.612$ \\
Needed & 2-3 Doses & 30 & 60.0 & 19 & 38.0 & 49 & 49.0 & $\mathrm{P}=0.000$ \\
> 3 Doses & & 00 & 0.0 & 23 & 46.0 & 23 & 23.0 & \\
\hline
\end{tabular}

Table IV B: Statistics of dose response interval to get the target BP among the study groups (With t-test significance).

\begin{tabular}{llrrrrrl}
$\begin{array}{l}\text { Target } \\
\text { variables }\end{array}$ & $\begin{array}{l}\text { Study } \\
\text { Groups }\end{array}$ & n & Mean & \pm SD & Median & Range & Sign.* \\
Total Dose & Group A & 50 & 1.72 & 0.67 & 2.00 & $1-3$ & $\mathrm{t}=7.122$ \\
Needed & Group B & 50 & 3.30 & 1.42 & 3.00 & $1-5$ & $\mathrm{P}=0.000$ \\
& Total & 100 & 2.51 & 1.36 & 2.00 & $1-5$ & $\mathrm{HS}$ \\
Total Time & Group A & 50 & 34.40 & 13.43 & 40.00 & $20-60$ & $\mathrm{t}=7.122$ \\
Needed & Group B & 50 & 66.00 & 28.36 & 60.00 & $20-100$ & $\mathrm{P}=0.000$ \\
(Minutes) & Total & 100 & 50.20 & 27.19 & 40.00 & $20-100$ & $\mathrm{HS}$ \\
\hline
\end{tabular}

*Independent samples

Table IVA and IVB showing results proportion of target BP achievement where $100 \%$ achievement was found in Group A and it was $72 \%$ in Group $\mathrm{B}(\mathrm{p}<0.05)$. Need of drug dose and time of reduction was found significantly less among Group A women $(\mathrm{p}<0.05)$.

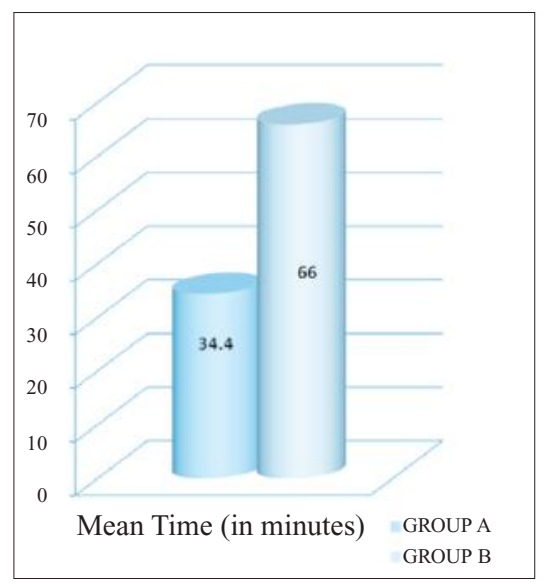

Figure 1 : Mean time needed to achieve the target among the study groups.

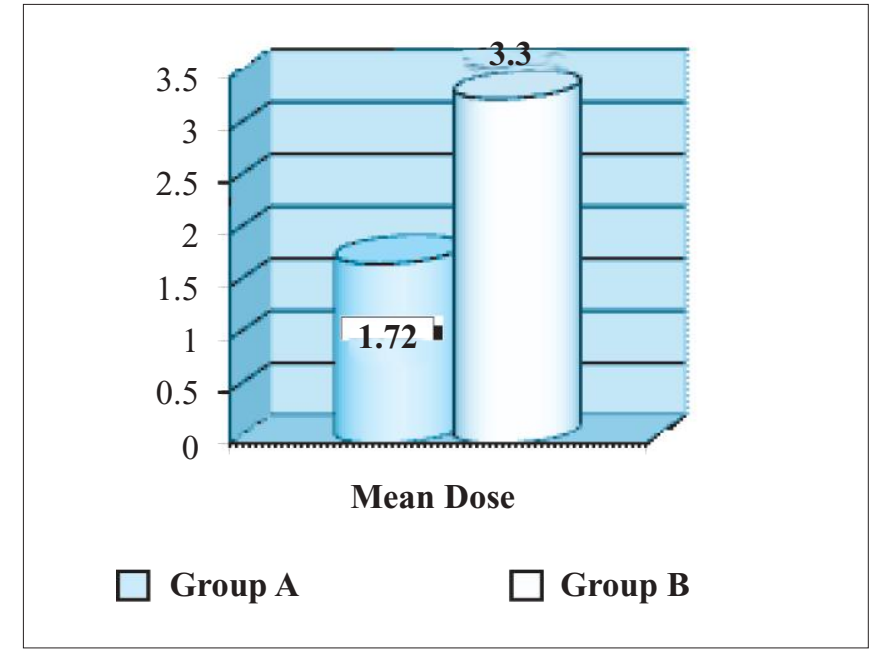

Figure 2 : Mean dose needed to achieve the target among the study groups.

Table V A : Distribution of feto-maternal complications among the study groups (With $\chi^{2}$ test significance).

\begin{tabular}{llllllllll} 
Feto-maternal & & \multicolumn{3}{c}{ Study Groups } & \multicolumn{2}{c}{ Total } & \multicolumn{2}{l}{$\chi^{2}$ Test } \\
complications & & Group A & \multicolumn{2}{c}{ Group B } & & & Significance \\
& & n & $\%$ & n & $\%$ & n & $\%$ & \\
Interference to & Needed & 23 & 46.0 & 31 & 62.0 & 54 & 54.0 & $\chi^{2}=2.576$ \\
expedite delivery & Not Needed & 27 & 54.0 & 19 & 38.0 & 46 & 46.0 & $\mathrm{p}=0.108$ \\
Side effects & Occurred & 02 & 4.0 & 04 & 8.0 & 06 & 6.0 & $\chi^{2}=0.709$ \\
& Not occurred & 48 & 96.0 & 46 & 92.0 & 94 & 94.0 & $\mathrm{p}=0.400$ \\
Fetal Outcome & Good & 34 & 68.0 & 30 & 60.0 & 64 & 64.0 & $\chi^{2}=1.583$ \\
& Ill & 12 & 24.0 & 12 & 24.0 & 24 & 24.0 & $\mathrm{p}=0.453$ \\
& Died & 04 & 8.0 & 08 & 16.0 & 12 & 12.0 & \\
\hline
\end{tabular}

Table VA showing complications of mother and fetus where more intervention needed among group B (54\% vs 46\%) side effects of drugs were found more in Group B ( $8 \%$ vs 4\%) and fetal death also more common in GroupB( $8 \%$ vs $16 \%)$ APGAR Score $>7$ Good. APGAR Score $<7$ ill.

Table V B : Distribution of maternal side-effects among the study groups (With $\chi^{2}$ test significance).

\begin{tabular}{llrrrrrrr} 
Maternal Side & \multicolumn{3}{c}{ Study Groups } & & Total & $\chi^{\mathbf{2}}$ Test \\
Effects & & Group A & Group B & & & Significance \\
& & n & $\%$ & N & $\%$ & N & $\%$ & \\
Headache & Occurred & 02 & 4.0 & 00 & 0.0 & 02 & 2.0 & $\chi^{2}=0.510$ \\
& Not Occurred & 48 & 96.0 & 50 & 100.0 & 98 & 98.0 & $\mathrm{p}=0.475$ \\
Nausea & Occurred & 02 & 4.0 & 00 & 0.0 & 02 & 2.0 & $\chi^{2}=0.510$ \\
& Not Occurred & 48 & 96.0 & 50 & 100.0 & 98 & 98.0 & $\mathrm{p}=0.475$ \\
Respiratory & Occurred & 00 & 0.0 & 04 & 8.0 & 04 & 4.0 & $\chi^{2}=2.344$ \\
distress & Not Occurred & 50 & 100.0 & 46 & 92.0 & 96 & 96.0 & $\mathrm{p}=0.126$ \\
\hline
\end{tabular}

Table VB shows that headache and nausea were found common in Group A women and none in Group B but respiratory distress was found in only Group B women. 


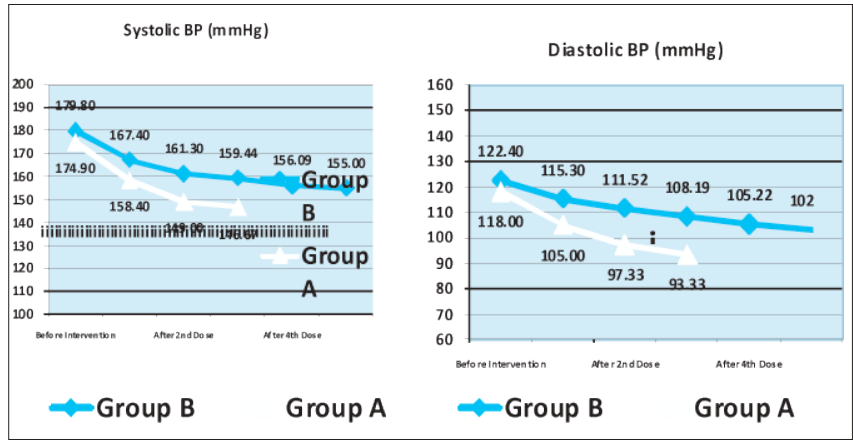

Figure 3 : Mean maternal pulse \& foetal heart rates on different occasions of intervention among the study groups.

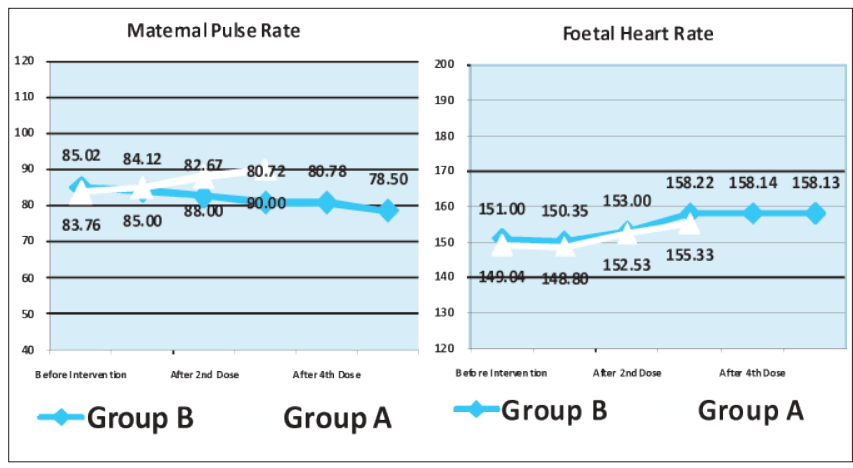

Figure 4 : Mean maternal pulse \& foetal heart rates on different occasions of intervention among the study groups.

Table VI : Distribution of APGAR score grading among the study groups (With $\chi^{2} \&$ t-test significance).

\begin{tabular}{lcccccccc} 
APGAR Score & \multicolumn{4}{c}{ Study Groups } & Total & $\begin{array}{r}\chi^{2} \text { Test } \\
\text { Grading }\end{array}$ \\
& & \multicolumn{2}{c}{ Group A } & \multicolumn{2}{c}{ Group B } & & & Significance \\
& & $\mathbf{n}$ & $\%$ & $\mathbf{n}$ & $\%$ & $\mathbf{n}$ & $\%$ & \\
APGAR Score & & & & & & & & \\
at 1 Minute & $<7$ & 18 & 36.0 & 24 & 48.0 & 42 & 42.0 & $\chi^{2}=1.478$ \\
& $\geq 7$ & 32 & 64.0 & 26 & 52.0 & 58 & 58.0 & $\mathrm{p}=0.224$ \\
APGAR Score & & & & & & & & \\
at 5 Minutes & $<7$ & 08 & 16.0 & 14 & 28.0 & 22 & 22.0 & $\chi^{2}=2.098$ \\
& $\geq 7$ & 42 & 84.0 & 36 & 72.0 & 78 & 78.0 & $\mathrm{p}=0.148$ \\
\hline
\end{tabular}

Table VI showing AGPAR score grading among both groups at 1 minutes and at 5 minutes. It was found that $\mathrm{AS}>7$ among Group A neonates was more than the Group B (84\% and 72\%).

Table VII : Data of urinary output at first hour among the study groups (With t-test significance).

\begin{tabular}{llllll} 
Variable & Study Groups & $\mathbf{n}$ & Mean & $\mathbf{\pm}$ SD & Sign.* \\
Urinary Output (ml) & Group A & 50 & 91.20 & 2.20 & $\mathrm{t}=91.148$ \\
& Group B & 50 & 42.20 & 3.10 & $\mathrm{p}=0.000$ \\
& TOTAL & 100 & 66.70 & 2.12 & HS \\
\hline
\end{tabular}

* Independent samples t-test. HS $=$ Highly Significant $(\mathrm{p}<0.001)$. Table VII showing urinary output where significant urine output volume was found in Group A patients than Group B $(\mathrm{p}<0.05)$.
Table VIII : Calculation of NNT to see the favourable outcome. Improvement between Nifedipine Vs Labetalol group.

\begin{tabular}{lllll} 
Patient category & \multicolumn{2}{c}{ Improved } & Lost to follow-up & Total \\
& Yes & Not & & \\
Nifedipine (Group A) & 50 (a) & 0 (b) & 0 & 50 \\
Labetalol (Group B) & 36 (c) & 14 (d) & 0 & 50 \\
\hline
\end{tabular}

$\operatorname{EER}=\mathrm{a} /(\mathrm{a}+\mathrm{b})=1, \mathrm{CER}=\mathrm{c} /(\mathrm{c}+\mathrm{d})=0.72, \mathrm{ARR}=($ ERR -

$\mathrm{CER})=0.28, \mathrm{RR}=(\mathrm{EER} / \mathrm{CER})=1.39$

$\mathrm{RRR}=(1-\mathrm{RR})=-0.39, \mathrm{NNT}=(1 / \mathrm{ARR})=3.57(4)$

4 patients have to be treated to get favourable outcome of 1 patient.

\section{*EER: $\quad$ Experimental Event Rate \\ CER: Control Event Rate}

ARR/ABI: Absolute Risk Reduction/ Absolute Benefit Increase

NNT: $\quad$ Number Needs to be Treated

RR: $\quad$ Relative Risk

RRR: $\quad$ Relative Risk Reduction

\section{DISCUSSION}

In the present study, 100 pregnant women with severe pregnancy induced hypertension were recruited where 50 patients were given oral nifedipine (Group-A) and 50 patients were administered $\mathrm{i} / \mathrm{v}$ labetalol (Group-B). It was seen that target BP achieved significantly more rapidly and with fewer doses in nifedipine group as compared with those receiving intravenous labetalol group. In this study, age were matched in both groups with a range of 20-30 years. Mean age in Nifedipine group is $26.14 \pm 6.26$ and in Labetalol group is $28.48 \pm 5.71$. Vermillion et al had the similar age group distribution in their study which is $27.2 \pm 7.3$ and $27.0 \pm 6.4$ for Nifedipine and Labetalol respectively ${ }^{14}$. Family history of hypertension was more common in labetalol group than the nifedipine group. There is poor association of family history of hypertension with pregnancy induced hypertension found in our study though family history is a risk factor of pregnancy induced hypertension. Multigravida patients were more than the primi patients in both groups (62\% in Nifedipine group and $72 \%$ in Labetalol group) which is similar to the study of Raheem et $\mathrm{al}^{15}$. Mode of delivery was mostly caesarian section in both groups .

Regarding results of proportion of target BP achievement where $100 \%$ achievement was found in Group A and it was $72 \%$ in Group B $(p<0.05)$. Need of drug dose and time of reduction was found significantly less among Group A women $(p<0.05)$. Nifedipine was found to be more efficacious than labetalol which is similar with Vermillion et $\mathrm{al}^{14}$. However, Raheem et al found both nifedipine and labetalol to be equally efficacious ${ }^{15}$. Shekhar et al and Dhali et al also found Nifedipine to be more efficacious which is also comparable to our study ${ }^{16,17} .100 \%$ success rate in achieving target BP with oral 
Nifedipine was found in this study. A study done Dhali et al where oral nifedipine achieved the goal therapeutic blood pressure more rapidly in $28.2 \pm 11.7$ minutes (Mean \pm SD) as compared with $48.4 \pm 23.5$ minutes in those received intravenous Labetalol $(\mathrm{p}=0.001)^{17}$. Whereas comparing with this study, it was $34,40 \pm 13,43$ minutes and $66 \pm 28.36$ minutes, respectively So their findings are consistent with this present study.

In the study by Raheem et al median times needed to achieve target BP were 30 minutes and 45 minutes in the nifedipine group and the labetalol group, respectively ${ }^{15}$. The shorter time needed to achieve target BP in comparison with that of the present study (Median time for Nifedipine and Labetalol $40 \mathrm{mi}-$ nutes and 60 minutes respectively) may be explained by the frequent dosing interval of 15 minutes used in their study compared with 20 minutes in the present study. In our study, the mean number of doses needed to achieve target blood pressure is $1.72 \pm 0.67$ and $3.30 \pm 1.42$ for nifedipine and labetalol respectively which is consistent with the findings of Vermillion et al where the mean dose for nifedipine is $1.5 \pm 0.5$ and for labetalol $2.5 \pm 1.5^{14}$. Shekhar et al found median dose required was two (Interquartile range 1-3) compared with three (interquartile range 2-4.25) for nifedipine and labetalol, respectively $(\mathrm{p}<.008)$ which also corresponds to our present study ${ }^{16}$.

The study may be questioned for using labetalol at 20-minute intervals instead of 15-minute intervals, as recommended by a few studies. We chose a 20-minute interval to keep the dosing interval the same for both drugs. Further, many other authors recommend 20-minute dosing frequency for oral nifedipine.

Regarding side effects, no serious adverse maternal effect was witnessed to either of the study groups. Minor side effects such as nausea, headache occurred in 2 patients of nifedipine group who were treated as per hospital protocol. Again respiratory distress occurred in 4 patients where 2 of them were cured by simple bronchodilator and for other two, medicine on call were made and bronchodilator, steroids were given to them. Similar study done by Vermillion et al and Dhali et al identified no significant adverse events attributed to either drug regimens ${ }^{14,17}$.

Maternal pulse rate before starting treatment in nifedipine group is $85.20 \pm 5.77$ and $83.72 \pm 3.48$ ( $p$ value $=.764$ ) and after third dose for nifedipine mpr is $87.33 \pm 2.73$ and for labetalol it is $83.78 \pm 3.63$. It means both the drugs did not have any significant influence in maternal pulse rate. This is similar to a study done by Shekhar et al where at enrollment maternal pulse rate in nifedipine and labetalol group was $88 \pm 9.3$ and $87 \pm 4$.9. At the end it was $86 . \pm 6.1$ and $97 \pm 10.3^{16}$.

Regarding APGAR score grading among both groups at $1 \mathrm{mi}-$ nutes and at 5 minutes. it was found that at 1 minute APGAR score $>7$ among Group A neonates was more than the Group $\mathrm{B}(64 \%$ and $52 \%$. $\mathrm{p}$ value $=0.224)$. At 5 minute APGAR score is ( $84 \%$ and $72 \%$, p value $=0.148$ ). APGAR score at 5 minutes $<7$ in nifedipine group is $16 \%$ and for $28 \%$ for labetalol group. Dhali et al compared the APGAR SCORE $<7$ at 5 minutes which is $3 \%$ and $14 \%$ for nifedipine and labetalol group respectively ${ }^{17}$. There was no significant difference in fetal adverse outcomes like intrauterine fetal heart abnormality. In our study mean FHR before intervention for nifedipine and labetalol group was 149.04 and 151.00 respectively. Again after the end of third dose it was 155.33 and 158.22 for nifedipine and labetalol group which was not significant. This is similar to the previous studies.

In our study, urine output was significantly increased $(\mathrm{p}<0.001)$ at one hour after nifedipine therapy $(91.20 \pm 2.20)$ compared with labetalol $(42.20 \pm 3.10 \mathrm{ml})$. This is consistent with the study by Dhali et al where urine output was significantly increased $(p<0.001)$ at one hour after nifedipine therapy $(95.6 \pm 1.2)$ compared with labetalol $(41.9 \pm 1.6 \mathrm{ml})^{17}$. Concerns have been raised about the safety of nifedipine in obstetric patients, such as possibility of overshoot hypotension with shortacting nifedipine with its maternal and fetal consequences and synergistic action with magnesium sulfate leading to profound neuromuscular blockade. All these concerns have been disproven by a number of trials evaluating nifedipine as an antihypertensive agent or as a tocolytic agent ${ }^{18-19}$. Calculated NNT was 3.57 (4) means for Nifedipine 4 patients has to be treated to have favourable outcome of one patient.

Our finding that nifedipine is more efficacious is at variance with the results of a previously conducted trial (With similar design) that found both drugs to be equally efficacious ${ }^{19}$. Although we have tried to analyze almost all the possible factors, it would be prudent to say that more analyses and a larger sample are required to derive the definite conclusion regarding difference in the effectiveness of nifedipine as compared with labetalol and to assess whether this difference is clinically significant.

In summary, nifedipine may be preferred because of its fewer dosing, rapidity for reduction of blood pressure, ease of oral administration, wide availability, and low cost.

\section{LIMITATIONS}

- Present study was done with small sample size and it was not double blinded.

- The study was done in a single center which is a tertiary level hospital. So women who were managed inside the hospital received maximum facilities for control of BP in severe PIH which do not represent the community scenario.

- Absence of long term follow up.

\section{CONCLUSIONS}

Oral nifedipine and intravenous labetalol both drugs are found to be effective in the management of severe PIH. But Nifedipine controls hypertension more rapidly with less doses and fetomaternal side-effects were also minimum with this drug.

\section{RECOMMENDATION}

Multi-center double blinded studies should be carried out involving bigger sample size with crossover design to get more reasonable results and to establish the efficacy and safety of oral Nifedipine in the treatment of severe pregnancy induced hypertension.

\section{DISCLOSURE}

All the authors declared no competing interest. 


\section{REFERENCES}

1. Lenfant C. National Education Program Working Group on High Blood Pressure in Pregnancy. Working group report on high blood pressure in pregnancy. J Clin Hypertens (Greenwich). 2001;3:75-88.

2. Sibai BM. Eclampsia. VI. Maternal-perinatal outcome in 254 consecutive cases. Am J Obstet Gynecol. 1990;163:1049-1054.

3. Shamsuddin L, Rouf S. Khalim H. Perinatal outcome of eclampsia patients. Bangladesh. J Obstet Gynecol. 1995; 10 (2) : 67. 22.

4. ACOG Committee on Obstetric Practice. ACOG practice bulletin. Diagnosis and management of preeclampsia and eclampsia. American College of Obstetricians and Gynecologists. Int J Gynaecol Obstet. 2002;77(33):67-75.

5. Giannubilo SR, Bezzeccheri V, Cecchi S, Landi B, Battistoni GI, Vitali P, Cecchi L, Tranquilli AL. Nifedipine versus labetalol in the treatment of hypertensive disorders of pregnancy. Arch Gynecol Obstet. 2012;286:637-642.

6. Khedun SM, Moodley J, Naicker T. Drug management of hypertensive disorders of pregnancy. Pharmacol Ther. 1997;74:221-258.

7. Mabie WC. Management of acute severe hypertension and encephalopathy. Clin Obstet Gynecol. 1999;42:519-531.

8. Linton DM, Anthony J. Critical care management of severe pre-eclampsia. Intensive Care Med. 1997;23:248-55.

9. Lamming GD, Broughton Pipkin F, Symonds EM. Comparison of the alpha and beta blocking drug, labetalol and methyl dopa in the treatment of moderate and severe pregnancy-induced hypertension. Clin Exp Hypertens. 1980;2:865-895.

10. Magee LA, Cham C, Waterman EJ, Ohlsson A, von Dadelszen P. Hydralazine for treatment of severe hypertension in pregnancy: Meta-analysis. BMJ. 2003;327:955-960.

11. Walters NJ,Redman WG. Treatment of servere pregnancy associated with hypertension with the calcium antagonist nifedipine. Br J Obsted Gynaecol. 1987; 91: 330-334.

12. Arias F, Daftary SN, Bhide AG. Practical Guide to High Risk Pregnancy \& Delivery. ${ }^{\text {rd }}$ edition,New Delhi:Elsevier. 2008;406-421.

13. Committee on Obstetric Practice. Committee Opinion no. 514: Emergent therapy for acute-onset, severe hypertension with preeclampsia or eclampsia. Obstet Gynecol. 2011;118:1465-1468.

14. Vermillion ST, Scardo JA, Newman RB, Chauhan SP. A randomized, double-blind trial of oral nifedipine and intravenous labetalol in hypertensive emergencies of pregnancy. Am J Obstet Gynecol. 1999;181:858-861.

15. Raheem IA, Saaid R, Omar SZ, Tan PC. Oral nifedipine versus intravenous labetalol for acute blood pressure control in hypertensive emergencies of pregnancy: A randomised trial. BJOG. 2012;119:78-85.

16. Dhali B, Bhattacharya S, Ganguly RP, Bandyopadhyay S, Mondal M, Dutta M. A randomized trial of intravenous labetalol \& oral nifedipine in severe pregnancy induced hypertension. Int J Reprod Contracept Obstet Gynecol. 2012 ;1(1):42-46.

17. Shekhar S, Sharma C, Thakur S, Verma Oral Nifedipine or Intravenous Labetalol for Hypertensive Emergency in Pregnancy A Randomized Controlled Trial. Obstetrics \& Gynaecology. 2013: 122(5): 1057-1062.

18. Meyer W, Randall HW, Graves WL. Nifedipine versus ritodrine for suppressing preterm labor. J Reprod Med. 1990;35:649-653.

19. Magee LA, Miremadi S, Li J, Cheng C, Ensom MH, Carleton B et al. Therapy with both magnesium sulfate and nifedipine does not increase the risk of serious magnesiumrelated maternal side effects in women with preeclampsia. Am J Obstet Gynecol. 2005;193:153-163. 